\title{
Changes in seawater nutrient concentrations during purse seine fishing for sardine Sardina pilchardus off northern Portugal
}

\author{
Yorgos Stratoudakis ${ }^{1, *}$, Ana Marçalo ${ }^{1,2}$, Carlos Vale ${ }^{1}$, Manuela Falcão ${ }^{2}$ \\ ${ }^{1}$ Instituto Nacional de Investigaçäo Agrária e das Pescas (INIAP/IPIMAR), Avenida de Brasilia s/n, 1449-006 Lisboa, Portugal \\ ${ }^{2}$ INIAP/IPIMAR, CRIP Sul, Avenida 5 de Outubro s/n, 8700-305 Olhão, Portugal
}

\begin{abstract}
Surface water samples were collected before, during and after purse seining for sardine off northern Portugal (12 sets) to test the hypothesis that fishing can lead to changes in local nutrient concentrations. Ammonia, urea, residual organic nitrogen and phosphate concentrations significantly increased during fishing and the increase was a pulse event associated with the drying-up of the net (when fish density in the net is highest). Concentrations at the end of fishing (on average 40 min after drying-up) were lower than peak values but still significantly higher than the original concentrations. Nitrate and nitrite did not alter during the fishing operation, further suggesting that the observed increase in nitrogen and phosphorus compounds is of biological origin. There was no significant relation between peak concentrations and fish catch, suggesting that the fisheriesassociated stimulus does not affect equally all the fish in the net (relative position in the net and fish condition may influence the probability of release). Published data on sardine nitrogen excretion and observations on nutrient concentrations in sardine body parts indicate that enhanced excretion of nitrogenous waste stimulated from stress reactions could account for the observed increase in ammonia and urea. Skin mucus release from scale loss (occurring extensively during the drying-up) is the most likely source of phosphorus, while forced evacuation of partly digested food items from the intestine or regurgitation from the stomach (both associated with the mechanical pressure and contact among fish and with the net walls at the end of drying-up) probably also contribute to the increase in residual organic nitrogen.
\end{abstract}

KEY WORDS: Sardine $\cdot$ Fishing $\cdot$ Confinement $\cdot$ Excretion $\cdot$ Stress $\cdot$ Nutrients

\section{INTRODUCTION}

Estimates of nitrogenous excretion rates are available for many fish species, although studies mainly focus on cultured species (e.g. Handy \& Poxton 1993) or small coastal species resistant to handling and easily adapted to laboratory conditions (e.g. Walsh et al. 2001). Comparatively little is known about small pelagic fish, which form a large part of the fish biomass in the world's continental shelves (mainly clupeoids) and, hence, in fisheries catches. It was recently estimated that sardine (Sardinops sagax) has an endogenous total nitrogen excretion rate of $28.1 \mathrm{\mu g} \mathrm{N} \mathrm{g}^{-1}$ dry body mass (DBM) $\mathrm{h}^{-1}$, with ammonia constituting $69 \%$ of the total (van der Lingen 1998). After feeding, excretion rates rapidly increased and ammonia excretion peaked at 60 to $90 \mu \mathrm{g} \mathrm{N} \mathrm{gDBM}{ }^{-1} \mathrm{~h}^{-1}$ during the 1.5 to $5 \mathrm{~h}$ after the initiation of phytoplankton feeding and at 45 to $195 \mu \mathrm{g} \mathrm{N} \mathrm{gDBM}^{-1} \mathrm{~h}^{-1}$ during 0.5 to $3 \mathrm{~h}$ after zooplankton feeding. These estimates are comparable with the few other studies on nitrogen excretion by small pelagic fish (McCarthy \& Whitledge 1972 for northern anchovy Engraulis mordax, Peruvian anchovy E. rigens and jack mackerel Trachurus symmetricus; Durbin \& Durbin 1981 for Atlantic menhaden Brevoor- 
tia tyrannus; and James et al. 1989b for Cape anchovy Engraulis capensis), although it is suggested that there is a decrease in endogenous ammonia excretion rates with increasing body size among clupeoids (van der Lingen 1998).

The ecological implications of fish-mediated nutrient recycling are usually studied at small spatial scales either in controlled lake microcosms (e.g. Attayde \& Hansson 2001) or in association with mariculture (e.g. Handy \& Poxton 1993). Very little is known about the nutrient loads released to the marine environment as a result of routine fish metabolism on a large spatial scale (McCarthy \& Whitledge 1972), and, to our knowledge, no study has so far examined the importance of fishing as a biological source of nutrient enrichment. Following visible changes in seawater colour during on-board observations of the purse seine fishing activity off northern Portugal (Stratoudakis \& Marçalo 2002), water samples were collected during commercial trips to test the hypothesis that fishing could lead to the rapid release of nutrients by sardine (Sardina pilchardus) confined in high densities within the net. In this study, we use chemical analysis of water samples collected during fishing to demonstrate that considerable loads of ammonia, urea, residual organic nitrogen and phosphate are released in a pulse during a distinct phase of the fishing operation. Further, we use published data on sardine excretion rates (van der Lingen 1998) and observations on nutrient concentrations in sardine body parts to identify possible sources and mechanisms for the observed release.

\section{MATERIALS AND METHODS}

The study took place from May to August 2002 on board commercial purse seine vessels of the Figueira da Foz fishing fleet in northern Portugal. Sampled trips were short (up to $12 \mathrm{~h}$ ), took place within half a degree of latitude from the home port $\left(39^{\circ} 46^{\prime}\right.$ to $\left.40^{\circ} 43^{\prime} \mathrm{N}\right)$ and usually resulted in a single setting of the net before sunrise. Fishing followed the typical purse-seine operation, involving the rapid deployment of a long net (up to $800 \mathrm{~m}$ long and $150 \mathrm{~m}$ deep) around marks of pelagic fish identified by the electronic fish-finding equipment, the closure of the bottom of the net (trapping the fish in a purse) and the drying-up of the net (gradually reducing the volume of the purse until the density of the fish becoming sufficiently high to start the transport on board). A trained observer followed 22 trips during the study period and collected water samples during the fishing operation. In 10 trips no fish were caught (failure to detect sufficiently dense schools, gear failures, bad weather, etc.), so water samples were only collected in 12 fishing operations.
The total catch (visually assessed by the skipper after the drying-up of the net) ranged between 1 and $17 \mathrm{t}$ set $^{-1}$ in the sampled trips, while landings (measured on board) ranged between $<1$ and $13 \mathrm{t}$. Similar to previous observations on the same fleet (Stratoudakis \& Marçalo 2002), sardine (Sardina pilchardus) formed the bulk of the catch (more than $95 \%$ in weight) and, in cases where the species catch exceeded the daily landing limits imposed by the local producer organisation (CENTROLITORAL), fish in excess were released by lowering the head-rope of the net at the end of the fishing operation. Small quantities of fish were occasionally released due to a mixture with the pelagic crab Polibius henslowi. The total duration of the fishing operation (from the setting of the net to the conclusion of the transfer of fish on board) was always less than $3 \mathrm{~h}$ and was usually proportional to the bulk of the catch.

Sardine samples were collected in 5 trips to perform basic biological analysis and to evaluate scale-loss associated to the fishing operation $(\mathrm{n}=78)$. Active fish were netted individually from the encircled area and carefully placed in plastic bags to minimise additional scale loss due to handling. In the laboratory, fish were measured and weighed and scale loss was visually evaluated. Fish condition was estimated as the ratio of total weight over the cube of total length. Mean total length of sampled sardine was $17.3 \mathrm{~cm}$ (range 13.9 to $20.2 \mathrm{~cm}$ ) and mean total weight was $48.7 \mathrm{~g}$ (range 23.3 to $72 \mathrm{~g}$ ), suggesting that relatively young fish (1 to $2 \mathrm{yr}$ olds) dominated the catch. Scale loss was evaluated as the proportion of body surface not covered with scales. To facilitate estimation, the fish body was divided into 3 sections (from head to dorsal fin; from dorsal fin to cloaca; and from cloaca to tail), and scale loss was separately evaluated in each section. No significant differences were found between sections, so total scale loss was expressed as the weighted mean of the sectional estimates for each fish.

Additional fish samples $(\mathrm{n}=43)$ were collected in commercial trips to identify nutrient levels within various body parts of sardine. Mean total length of sampled sardine was $18.3 \mathrm{~cm}$ (range 16.7 to $20.3 \mathrm{~cm}$ ) and mean total weight was $49.7 \mathrm{~g}$ (range 36.7 to $67.2 \mathrm{~g}$ ), very similar to the fish size distribution observed during the collection of water samples. Stomach and intestine contents, scales and skin mucus were isolated and weighed (wet weight) from each fish. All contents were frozen at $-20^{\circ} \mathrm{C}$ for subsequent chemical analysis. After defrosting, each sample was diluted in $250 \mathrm{ml}$ of seawater. Samples were then filtered and analysed following the procedures described below for the analysis of water samples, to estimate the concentration of ammonia, phosphate, nitrate, nitrite and total nitrogen per unit of wet weight (urea was not separately estimated in this case). 
Water samples (5 replicates of $200 \mathrm{ml}$ ) were collected on each trip during 3 phases of the fishing operation: the end of the setting-up of the net (control, Phase I); the end of the drying-up of the net (when maximum fish densities are attained, just prior to the onset of the transfer of fish to the vessel, Phase II); and the end of the fishing operation (just before leaving the fishing ground, Phase III). On average, Phase I sampling occurred 35 min after the start of the fishing operation (range 20 to $60 \mathrm{~min}$ ), coinciding with the early phases of net hauling. Phase II sampling occurred on average $80 \mathrm{~min}$ after the onset of fishing (range 60 to $100 \mathrm{~min}$ ) and Phase III sampling occurred on average $40 \mathrm{~min}$ later (range 75 to $150 \mathrm{~min}$ ). Sampling during each phase was practically instantaneous. On the last 3 fishing trips, sampling was intensified, with 3 samples added between Phases I and II and another sample added between Phases II and III at approximately regular intervals ( 3 replicates of $200 \mathrm{ml} \mathrm{sample} \mathrm{s}^{-1}$ ).

All water samples were immediately frozen and maintained at $-10^{\circ} \mathrm{C}$ until laboratory analysis. Water samples were filtered through $0.45 \mu \mathrm{m}$ Nucleopore membranes and analysed individually for phosphates, nitrates, nitrites, ammonia, urea and total dissolved nitrogen. Phosphate, nitrate, nitrite, and ammonia were analysed using a Skalar autoanalyser according to Technicon Industrial Systems (Grasshoff 1983). Urea was determined after the formation of a coloured complex at $520 \mathrm{~nm}$ using a Hitachi spectrophotometer (Grasshoff 1983). Total dissolved nitrogen was measured after digestion with potassium peroxidisulphate in autoclave $\left(1.5 \mathrm{bar} 120^{\circ} \mathrm{C}\right)$ as described in Grashoff (1983). Residual organic nitrogen was estimated from total dissolved nitrogen after subtracting total inorganic nitrogen (nitrate, nitrite and ammonia) and urea concentrations.

Given the unbalanced nature of sampling (varying number of replicates per phase among trips, no sampling of Phase III at the second trip), the effect of sampling phase on nutrient concentration was tested using linear mixed models (Pinheiro \& Bates 2000), with phase as the fixed effect and sampled trip as the random effect. The effect of phase on nitrite and residual organic nitrogen concentrations was only tested in a sub-set of the data, as these compounds were only measured in the last 6 trips. All variables were logtransformed to approximate better the normality and homogeneity of variance assumptions. Pairwise comparisons among the fitted effects in the 3 phases were made using approximate $t$-tests, after correcting for multiple comparisons (by multiplying the probability values by the number of comparisons). Similarly, the effect of fish biomass on peak nutrient concentrations (Phase II) was tested using linear mixed models, with biomass a fixed effect and sampled trip a random effect. Correlations between compound concentrations in each water sample were tested using the Spearman rank correlation test, separately for each phase. Finally, differences in length, weight and condition factor between damaged (visual evidence of scale loss) and undamaged (no scale loss) fish were tested with $t$-tests on the pooled data from the 5 trips where biological samples were taken. Statistical analysis was performed using the open source software R (version 1.6.1) and mixed-effect models were fitted using the library nlme (Pinheiro \& Bates 2000).

\section{RESULTS}

Summary boxplots of the seawater concentration $(\mu \mathrm{M})$ of the 6 compounds analysed are shown in Fig. 1 for each phase of the fishing operation. Concentrations during Phase I were very close to those reported from oceanographic studies on the Portuguese continental shelf (e.g. Falcão 1996, Cabeçadas et al. 2002), thus justifying their use as base levels for comparison. There was a considerable increase in phosphate, ammonia, urea and residual organic nitrogen concentration during the drying-up of the net (Phase II), while at the end of fishing (Phase III) concentrations were higher than the base levels but lower than the peak values in Phase II. Fig. 1 also suggests that nitrate and nitrite concentrations remained relatively stable during the fishing operation. All pairwise comparisons between phases were highly significant for ammonia, urea, residual organic nitrogen and phosphate and non-significant for nitrate and nitrite (Table 1). Phosphate was the compound with the highest relative increase in Phase II (74 times the mean base level), temporarily altering the local environment from $\mathrm{P}$-deficient to $\mathrm{N}$-deficient (according to the Redfield ratio). Although residual organic nitrogen showed the lowest relative increase ( 5 times the base level), in absolute terms it was the compound that increased most during Phase II.

The significantly lower mean concentration of ammonia, urea, residual organic nitrogen and phosphate during Phase III suggests that local enrichment is relatively short-lived and occurs at some stage of the fishing operation up to the onset of the fish transfer on board. To describe in more detail the dynamics of the phenomenon, sampling was intensified in the last 3 of the sampled trips. Fig. 2 shows similar boxplots for the 4 compounds on the trips where water samples where collected during 7 time intervals. The temporal evolution of concentration is very similar for the 4 compounds, indicating that the observed increase in nutrients is mainly associated with a pulse event during the end of the drying-up of the net. It is worth noting that the sampling interval between Phase I. 3 and Phase II is 

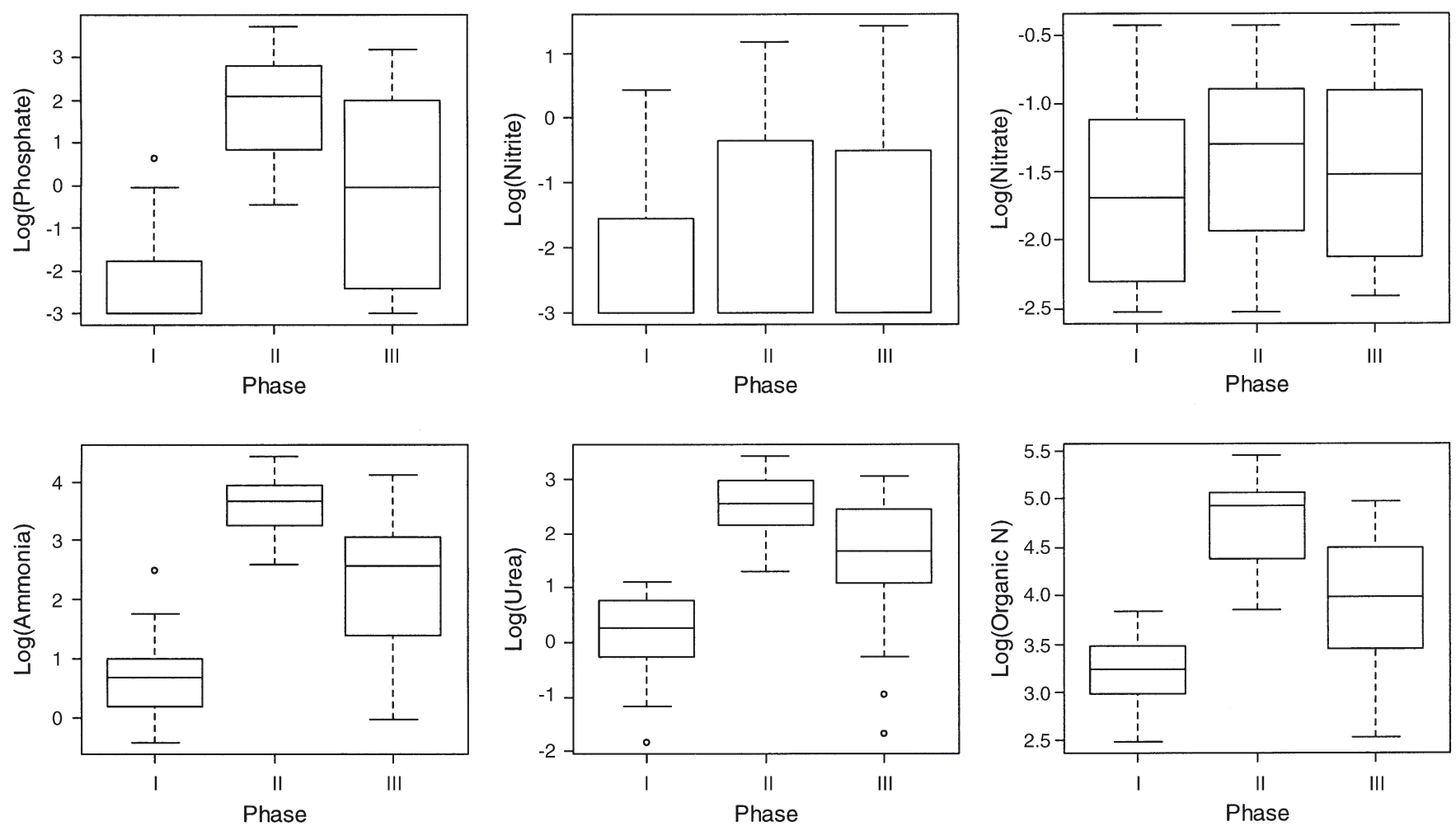

Fig. 1. Boxplots of phosphate, nitrite, nitrate, ammonia, urea and residual organic nitrogen log-concentration ( $\mu \mathrm{M})$ in water samples collected in the 3 phases of each fishing trip. Nitrite and residual organic nitrogen were only measured on 6 trips. o: outlier

approximately 15 to $20 \mathrm{~min}$, in which period concentrations for the 4 compounds increased considerably. Also, the 10 to 15 min interval from Phase II to Phase II.1 is sufficient to demonstrate a reduction in the concentration of the 3 nitrogen compounds.

Peak nutrient concentrations were not related to fish biomass in the net (all models on the effect of biomass on compound peak concentration were nonsignificant), despite biomass differences of an order of magnitude among trips (1 to $17 \mathrm{t}$, approximately corre-

Table 1. Results of linear mixed models for testing differences in mean concentration of nutrients during the 3 phases of sampling. Mean values $(\mu \mathrm{M})$ are the fitted parameters of the linear mixed models, back-transformed to the original scale (exponent). Pairwise comparisons refer to $t$-values. Significance after adjusting $p$-values for multiple comparisons: ns, non-significant; ${ }^{*} 5 \%$; ${ }^{* *} 1 \%$; ${ }^{* * *} 0.1 \%$

\begin{tabular}{|lrrrrrrrr|}
\hline \multirow{2}{*}{ Compound } & \multicolumn{3}{c}{ Mean value } & & & \multicolumn{3}{c|}{ Pairwise comparison -} \\
\cline { 2 - 4 } \cline { 7 - 8 } & Phase I & Phase II & Phase III & & I vs II & I vs III & II vs III \\
\hline Nitrate & 0.16 & 0.16 & 0.16 & & $0.15 \mathrm{~ns}$ & $-0.15 \mathrm{~ns}$ & $-0.30 \mathrm{~ns}$ \\
Nitrite & 0.17 & 0.21 & 0.20 & & $-1.77 \mathrm{~ns}$ & $-1.34 \mathrm{~ns}$ & $0.88 \mathrm{~ns}$ \\
Ammonia & 1.97 & 35.77 & 14.01 & & $-17.23^{* * *}$ & $-8.87^{* * *}$ & $8.36^{* * *}$ \\
Urea & 1.17 & 13.53 & 4.72 & & $-13.48^{* * *}$ & $-7.68^{* * *}$ & $5.80^{* * *}$ \\
Organic N & 25.74 & 123.72 & 53.41 & & $-14.61^{* * *}$ & $-6.71^{* * *}$ & $7.73^{* * *}$ \\
Phosphate & 0.10 & 7.36 & 0.68 & & $-14.04^{* * *}$ & $-6.32^{* * *}$ & $7.72^{* * *}$ \\
& & & & & & & & \\
\hline
\end{tabular}

sponding to $2 \times 10^{4}$ to $3.2 \times 10^{5}$ fish set $^{-1}$ ). Although the small sample size $(\mathrm{n}=12)$ may reduce the power to detect a significant relation, another plausible explanation is that only a fraction of the encircled fish contributes to the release of $\mathrm{N}$ and $\mathrm{P}$ compounds and this fraction is inversely related to fish catch. The examination of sardine scale loss during the fishing operation demonstrated wide variation in physical damage among individuals, with $32 \%$ of the sampled fish not showing any evidence of scale loss and $21 \%$ having practically lost all scales. Interestingly, a significant biological difference $(t=2.23 ; \mathrm{p}=0.03)$ was found between intact and damaged fish, the latter having on average a lower condition factor than the former (Fig. 3). It is thus possible that the release of $\mathrm{N}$ and $\mathrm{P}$ compounds is primarily due to the individuals that are least capable of avoiding physical contact with other fish and the net during the fishing operation and that the number of affected fish is more related to the geometry of the encircled area than the size of the catch (the area/ volume ratio becomes lower with increasing catch). 

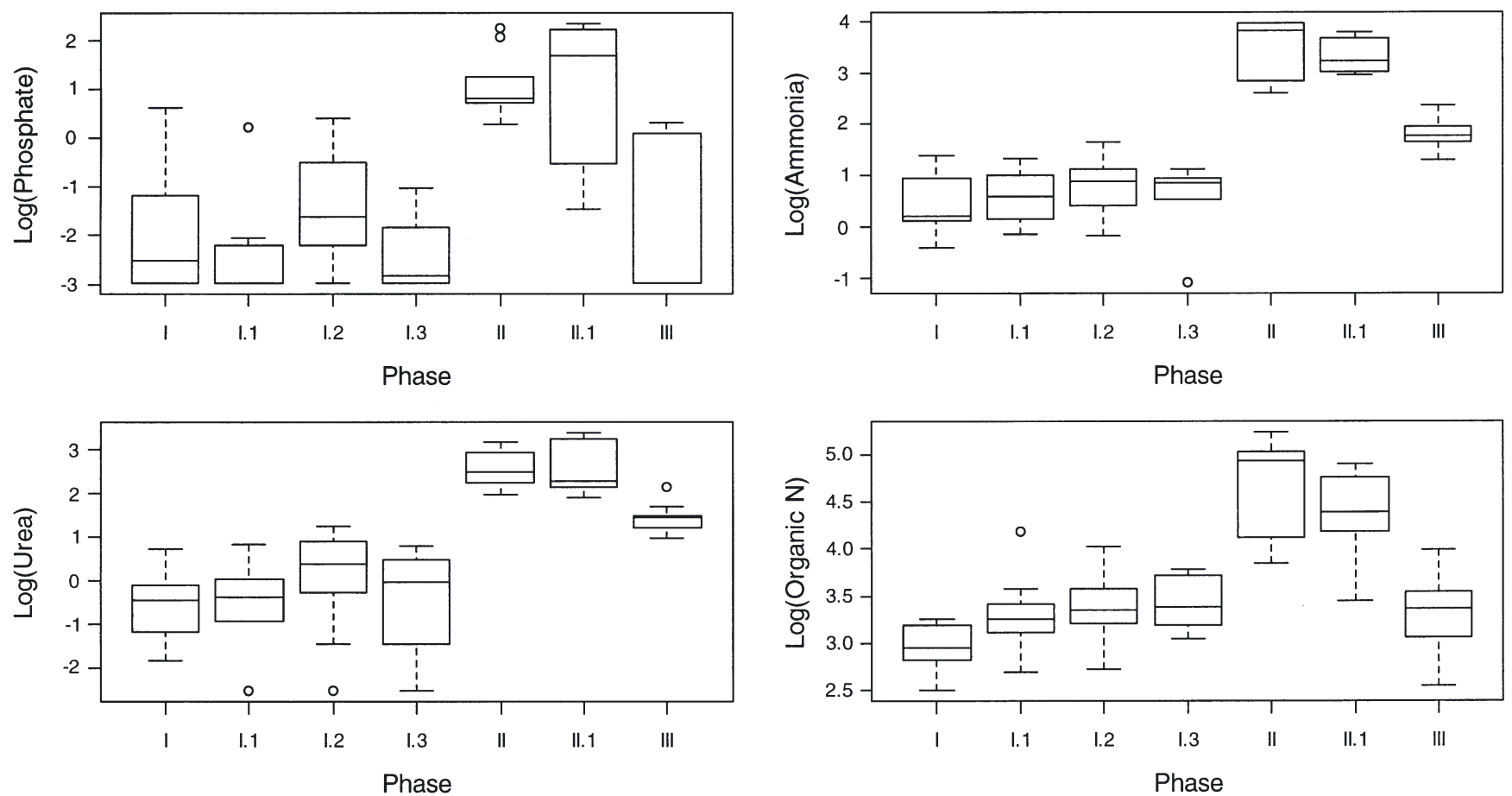

Fig. 2. Boxplots of phosphate, ammonia, urea and residual organic $\mathrm{N}$ log-concentration $(\mu \mathrm{M})$ in intensified water sampling during the last 3 fishing trips. Phases I.1, I.2 and I.3 indicate samples taken between Phases I and II, and Phase II.1 indicates samples taken between Phases II and III. o: outlier
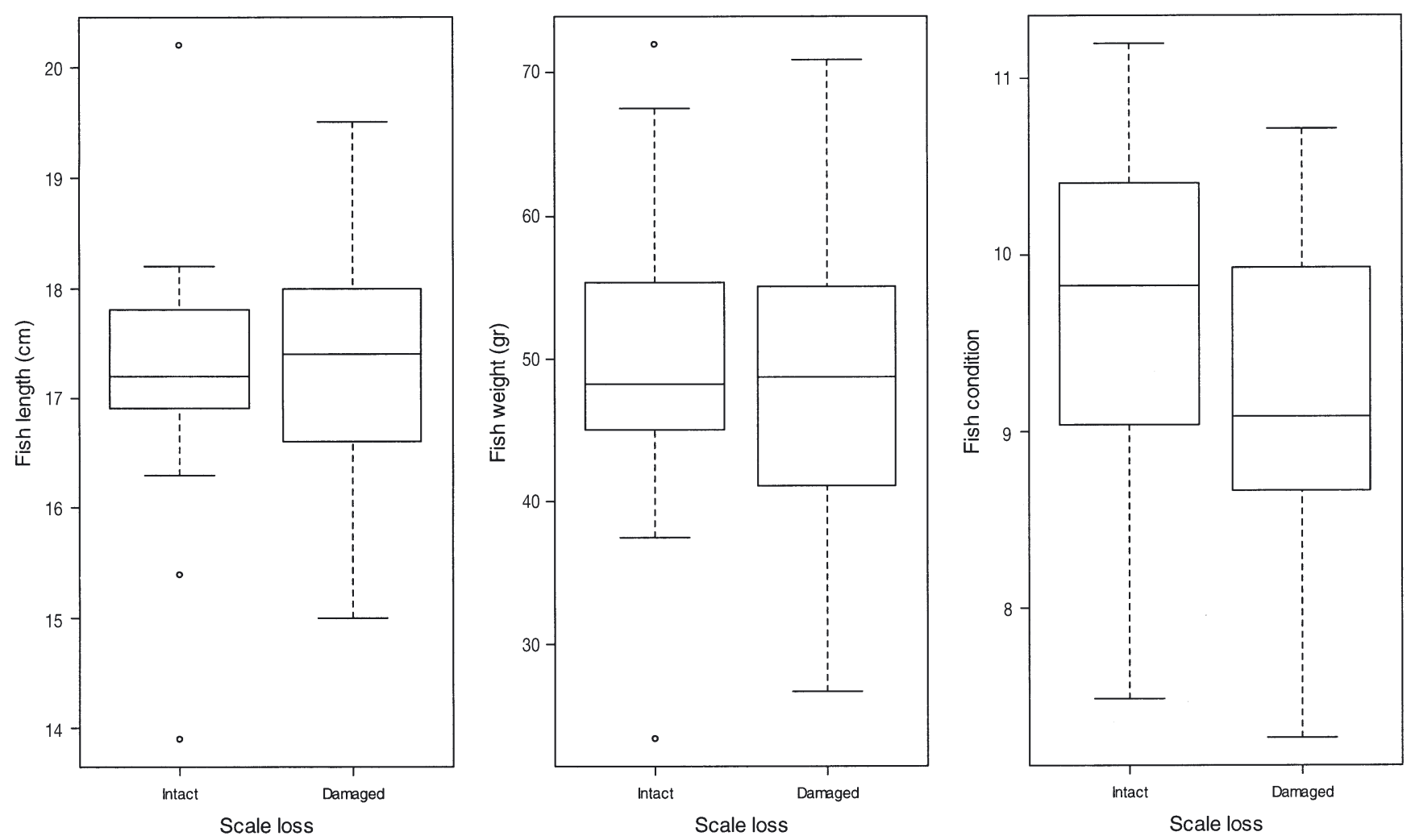

Fig. 3. Sardina pilchardus. Boxplots of total length, total weight and condition factor for fish with (damaged) and without (intact) scale loss during the observed trips. Difference in condition factor between the 2 groups is significant at the $5 \%$ level. o: outlier 
Table 2. Spearman rank coefficients for correlations between compounds during each phase of sampling. Significance: ns, nonsignificant; ${ }^{*} 5 \% ;{ }^{* *} 1 \% ;{ }^{* * *} 0.1 \%$

\begin{tabular}{|lrll|}
\hline Compounds & Phase I & Phase II & Phase III \\
\hline Ammonia - urea & $0.139 \mathrm{~ns}$ & $0.441^{* *}$ & $0.825^{* * *}$ \\
Ammonia - phosphate & $0.083 \mathrm{~ns}$ & $0.343^{*}$ & $0.632^{* * *}$ \\
Ammonia - residual organic N & $0.112 \mathrm{~ns}$ & $0.354 \mathrm{~ns}$ & $0.592^{* * *}$ \\
Urea - phosphate & $-0.251 \mathrm{~ns}$ & $0.802^{* * *}$ & $0.586^{* * *}$ \\
Urea - residual organic N & $0.385 \mathrm{~ns}$ & $-0.010 \mathrm{~ns}$ & $0.426^{*}$ \\
Phosphate - residual organic N & $-0.200 \mathrm{~ns}$ & $0.100 \mathrm{~ns}$ & $0.678^{* * *}$ \\
& & & \\
\hline
\end{tabular}

Although ammonia, urea, residual organic nitrogen and phosphate attained their highest concentrations during Phase II, Table 2 demonstrates that the finescale dynamics (and possibly the mechanisms) of release may differ among compounds. As expected, concentrations of the 4 compounds within water samples were not significantly correlated during Phase I, confirming that these samples represent an appropriate control for testing potential effects due to fishing. This contrasts with Phase III, in which all pairwise combinations of compounds were significantly correlated (in most cases significant at the $0.1 \%$ level). However, during Phase II (peak concentration for all compounds) ammonia, urea and phosphate in the water samples were correlated with each other, but not with residual organic nitrogen. This lack of correlation and slight differences in the temporal evolution (the latter compound showed a slight increase from the onset of fishing - Fig. 2) possibly indicate that the release of residual organic nitrogen is the result of a different process to that leading to the release of the other 3 compounds.

To infer the possible source and mechanism of release for each compound, nutrient analysis was also performed on distinct sardine body parts (stomach and intestine contents as well as skin mucus with scales). Nitrate and nitrite concentrations were residual in all body parts, while organic nitrogen (including urea) was the most abundant compound. The concentration ( $\mu \mathrm{mol} g$ wet weight ${ }^{-1}$ ) and content ( $\mu \mathrm{mol}$ per fish) of ammonia, organic nitrogen and phosphate varied among body parts (Fig. 4). Concentrations were generally highest in the intestine and lowest in the skin and mucus, with nitrogenous compounds being also highly concentrated in the stomach. However, when the total amount of each compound was considered for each sampled fish (content), the differences in nitrogenous compounds between body parts were greatly re-


Fig. 4. Sardina pilchardus. Boxplots of ammonia, organic nitrogen and phosphate concentrations ( $\mu$ mol g wet weight ${ }^{-1}$, upper panels) and contents ( $\mu \mathrm{mol}$ per fish, lower panels) in stomach contents, intestine contents and scales with skin mucus (n = 43). o: outlier 
Table 3. Comparison of ammonia, organic nitrogen and phosphate concentrations $(\mu \mathrm{M})$ in sardine body parts (from Fig. 4), fish excretion (from feeding experiments for Sardinops Sagax; van der Lingen 1998) and observations in seawater during the drying-up of the net (from Table 1). na: not available

\begin{tabular}{|llrrc|}
\hline \multirow{2}{*}{ Source } & \multicolumn{1}{c}{ Situation } & Ammonia & Organic N & Phosphate \\
\hline Sardine body & Stomach & 1.7 & 35.5 & 1.8 \\
parts & Intestine & 3.1 & 39.6 & 4.0 \\
& Mucus+scales & 2.5 & 35.1 & 8.7 \\
Excretion & Base & 17.0 & 3.0 & na \\
& After fed phytoplankton & 80.5 & 13.0 & na \\
& After fed zooplankton & 174.0 & 28.5 & na \\
Seawater & Phase II & 35.8 & 137.2 & 7.4 \\
\hline
\end{tabular}

duced, while skin and mucus had a significantly higher content of phosphate than the stomach and intestine.

Table 3 compares the concentration $(\mu \mathrm{M})$ of compounds resulting from excretion (data from van der Lingen 1998), sardine body part contents and those observed in the water samples during the drying-up of the net. The tabulated excretion concentrations represent the release of ammonia and organic nitrogen by a sardine of $50 \mathrm{~g}$ wet weight in $1 \mathrm{~h}$ during starvation (endogenous rate) and maximal levels of excretion after it was fed phytoplankton and zooplankton diets respectively. Body part concentrations represent the mean content of ammonia, organic nitrogen (including urea) and phosphate (Fig. 4) of a sardine diluted in 11 of water (the mean weight of sardines used for the analysis of body part contents was $50 \mathrm{~g}$ ). Given that sardine density in the net during the drying up was approximately 1 fish litre ${ }^{-1}$, the excretion and body part concentrations can be directly compared to the mean nutrient concentration in the water samples during Phase II (Table 1).

\section{DISCUSSION}

This study demonstrates that highly significant increases in ammonia, urea, residual organic nitrogen and phosphate concentrations occur in surface waters during commercial purse-seine fishing for sardine. Although fishing is known to redistribute energy and matter in the water column through fish being discarding (Alverson et al. 1994), to our knowledge, this is the first time that fishing has been demonstrated to have a direct influence on the biogeochemical cycle of nitrogen and phosphorus in coastal marine waters. Nutrient enrichment takes the form of a pulse that occurs within a very short time interval (probably less than $30 \mathrm{~min}$ ) during the end of the drying-up of the net, when maximum fish densities are attained within the net. The almost simultaneous increase in various compounds and the correlation between peak values indicate that the observed nutrient release results from a stimulus associated with the fishing operation, while the lack of change in nitrites and nitrates provides additional evidence that the release is of biological origin.

One possible source of the nitrogenous compounds released during fishing is metabolism, through the excretion of nitrogen waste at a rate possibly enhanced by stress reactions due to severe exercise, crowding and confinement within the net (Chopin \& Arimoto 1995). However, this can only account for the release of ammonia (and eventually urea), given that sardine, like the majority of teleost fish, are predominantly ammoniotelic (van der Lingen 1998). Assuming that the ammonia excretion rates measured in Sardinops sagax are valid for Sardina pilchardus, Table 3 shows that the observed peak concentrations of ammonia in the sea water could have resulted from the excretion of recently fed sardine within a short period (less than $1 \mathrm{~h}$ ). Further, Hopkins et al. (1995) demonstrated that acute confinement/crowding can lead to almost immediate stress reactions (plasma cortisol levels peaking within $2 \mathrm{~h}$ ) and that the total nitrogen excretion rate had a strong relationship with cortisol concentration in the plasma of the ureogenic toadfish Opsanus beta. Despite the differences in nitrogen metabolism between the 2 species, blood samples collected in the same trips indicate that cortisol levels in the plasma of sardine increase significantly during purse seining (A. Marçalo unpubl. data), thus rendering plausible the fact that the main mechanism leading to increased ammonia concentration is a stress-induced enhancement of sardine excretion.

Table 3 also shows that fish excretion could not account for the very high levels of organic nitrogen and phosphates observed in the seawater. Nitrogenous compounds other that urea and ammonia are also known to be excreted by fish (e.g. creatine, uric acid, purines, dipeptides, etc.) but their quantitative importance is believed to be relatively small (McCarthy \& Witledge 1972, van der Lingen 1998) and their mechanisms of excretion are poorly understood (Walsh et al. 2001). Even less is known about the metabolism of phosphorus in teleosts, but its important physiological role, lack of toxicity and deficiency in coastal seawaters suggest that routine release is unlikely. The analysis of sardine body parts (Table 3 ) indicated that surface skin layers and mucus are particularly rich in phosphates, whereas organic nitrogen (mainly in reduced complex forms) is also abundant in the stomach and the intestine. It is therefore plausible that the observed increase in dissolved organic nitrogen and 
phosphates in the seawater during the drying-up of the net result from the combined effect of skin abrasion, regurgitation of stomach contents and forced evacuation of partly digested food.

Although the sources and specific mechanisms that lead to the release of various nitrogenous compounds and phosphates during fishing are different, they all seem to be triggered by the highly stressful and traumatic operation of the drying-up of the net. In the short period prior to the onset of fish transfer on board, fish densities in the net become very high (reaching or exceeding $10^{3}$ fish $\mathrm{m}^{-3}$ ) and escape reactions become visibly more frequent (bursts of disoriented swimming, jumps, gulps for air, etc.). Severe exercise, crowding and confinement lead to the rapid build-up of stress that possibly triggers the excretion of ammonia and urea, while causing extensive scale loss through abrasion (in one trip scale densities in the water were counted at each phase, showing no scale loss in Phase I and scale densities of ca $115000 \mathrm{~m}^{-3}$ in Phase II, which reduced by an order of magnitude in Phase III). Extensive scale loss, which has also been observed in other purse-seine fisheries (Lockwood et al. 1983, James et al. 1989a), is associated with the release of surface skin layers and mucus, which contribute to the increase in phosphates and organic nitrogen concentrations. Finally, high fish densities and handling can lead to mechanical pressure on the fish, particularly in the areas closest to the net walls, possibly causing regurgitation of recently ingested food and forced evacuation of partially digested food items, further contributing to the increase in dissolved organic nitrogen in reduced forms.

The above sequence of events probably occurs in all purse-seine sets where the catch is dominated by sardine, a fragile species that is sensitive to crowding and manipulation (James et al. 1989a). However, the lack of correlation between sardine catch and peak nutrient concentration observed in this study probably indicates that the impact of fishing is not equal to all individuals. One likely explanation is that stress build-up and mechanical damage is more likely to affect fish close to the net walls, thus being proportional to the area of the net during drying-up and not to the volume of the catch. Another possible explanation is that fish condition can modulate the impact of the fishing operation in terms of physiological reactions and, eventually, survival (Chopin \& Arimoto 1995). The latter is supported by the finding that within the same sets the probability of scale loss was significantly higher for sardine that had a lower condition factor, but cannot be tested across sets, since biological data were not collected in all trips. In any case, the hypothesis that fish condition may influence the response to the fishing gear seems plausible and deserves attention in future studies of fish-gear interactions.
Acknowledgements. We thank the Producer Organisation CENTROLITORAL and its chairman, A. M. Lé, for their support in the fieldwork, M. Santos (IPIMAR-CRIP Sul) for the chemical analysis and 3 anonymous referees for their constructive criticism of the original manuscript. This work was funded by the Portuguese Ministry of Science and Higher Education through the restructuring programmes PELAGICOS (MLE 013/2000, affiliated to GLOBEC/SPACC) and MACAC (MLE 012/2000). A.M. was partially supported by a scholarship from the Portuguese Ministry of Foreign Affairs.

\section{LITERATURE CITED}

Alverson DL, Freeberg MH, Murawski SA, Pope JG (1994) A global assessment of fisheries bycatch and discards. FAO Fish Tech Pap No 339, FAO, Rome

Attayde JL, Hansson LA (2001) Fish-mediated nutrient recycling and the trophic cascade in lakes. Can J Fish Aquat Sci 58:1924-1931

Cabeçadas G, Brogueira MJ, Gonçalves C (2002) The chemistry of Mediterranean outflow and its interactions with surrounding waters. Deep Sea Res II 49:4263-4270

Chopin FS, Arimoto T (1995) The condition of fish escaping from fishing gears - a review. Fish Res 21:315-327

Durbin EG, Durbin AG (1981) Assimilation efficiency and nitrogen excretion of a filter-feeding planktivore, the Atlantic menhaden, Brevoortia tyrannus (Pisces: Clupeidae). Fish Bull 81:601-616

Falcão MM (1996) Nutrient dynamics in Ria Formosa: effects of the interaction between the lagoon and its interfaces in the recycling of nitrogen, phosphorus and silica. $\mathrm{PhD}$ thesis, University of Algarve, Faro (in Portuguese)

Grasshoff K (1983) Methods of seawater analysis. VerlagChemie, New York

Handy RD, Poxton MG (1993) Nitrogen pollution in mariculture: toxicity and excretion of nitrogenous compounds by marine fish. Rev Fish Biol Fish 3:205-241

Hopkins TE, Wood CM, Walsh PJ (1995) Interactions of cortisol and nitrogen metabolism in the ureogenic gulf toadfish Opsanus beta. J Exp Biol 198:2229-2235

James AG, Hutchings L, Brownell CL, Horstman DA (1989a) Methods of capture and transfer to the laboratory of wild pelagic fish. S Afr J Mar Sci 6:17-21

James AG, Probyn T, Seiderer LJ (1989b) Nitrogen excretion and absorption efficiencies of the Cape anchovy Engraulis capensis Gilchrist fed upon a variety of plankton diets. J Exp Mar Biol Ecol 131:101-124

Lockwood SJ, Pawson MG, Eaton DR (1983) The effects of crowding on mackerel (Scomber scombrus L.) - physical condition and mortality. Fish Res 2:129-147

McCarthy JJ, Whitledge TE (1972) Nitrogen excretion by anchovy (Engraulis mordax and E. rigens) and jack mackerel (Trachurus symmetricus). Fish Bull 70:395-401

Pinheiro JC, Bates DM (2000) Mixed-effects models in S and S-PLUS. Springer-Verlag, New York

Stratoudakis Y, Marçalo A (2002) Sardine slipping during purse seining off northern Portugal. ICES J Mar Sci 59: $1256-1262$

van der Lingen CD (1998) Nitrogen excretion and absorption efficiencies of sardine Sardinops sagax fed phytoplankton and zooplankton diets. Mar Ecol Prog Ser 175:67-76

Walsh PJ, Wang Y, Campbell CE, De Boeck G, Wood CM (2001) Patterns of nitrogenous waste excretion and gill urea transporter mRNA in several species of marine fish. Mar Biol 139:839-844 